\title{
An investigation into the use of speech acts and language functions in Iranian high school English textbooks
}

Roohani, Ali

Shahrekord University, Iran (roohani.ali@gmail.com)

Alipour, Javad $\bigotimes$

Shahrekord University, Iran (alipour.edu@gmail.com)

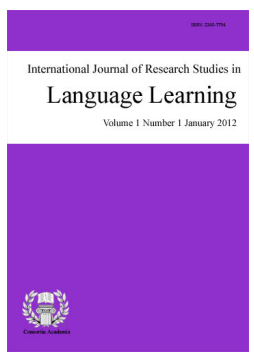

ISSN: 2243-7754 Online ISSN: 2243-7762

OPEN ACCESS

\section{Abstract}

Criticism has been leveled against English textbooks on the grounds that they often fail to provide classroom learners with adequate opportunities for learning authentic language (Vellenga, 2004). This could be due to the fact that, instead of making use of authentic language samples native speakers produce, many textbooks draw on native speakers' intuitions about language use, which might not always be reliable. This study investigated the use of speech acts presented in Iranian high school English Textbooks I, II, and III. To this end, speech acts in the conversations segments of these books were analyzed from the perspective of Searle's (1976) speech act model and Lakoff's (1973) view of politeness. The results revealed that there were, in total, 298 instances of speech acts used in high school textbooks. It was also found that language functions in these books are presented unequally and some of them recur throughout the books, with no specific pattern being followed. Since high school English textbooks in Iran are not communication-oriented, it was concluded that these books cannot possibly develop pragmatic competence in language learners.

Keywords: speech acts; language functions; high school English textbooks; politeness 


\section{An investigation into the use of speech acts and language functions in Iranian high school English textbooks}

\section{Introduction}

As teachers of English as a foreign language, we have all seen students who are able to produce grammatically correct utterances which are not appropriate for the context in which they are used. For example, a student who, in response to "Could you help me, please?", says "Yes, I could" instead of "Sure, it would be my pleasure", might be grammatically competent. However, they may not know how to use it appropriately. Teaching pragmatics has occupied an important role in ESL/EFL curricula (Eslami-Rasekh, 2005; Olshtain \& Cohen, 1991). However, language learners' overall development of pragmatic competence has proved to be very challenging in English as a Foreign Language (EFL) contexts. Therefore, second language learners' awareness of the target language use should be developed along with linguistic competence" (Blum-Kulka et al., 1989, p. 10).

In this regard, language teachers should remind their learners that effective communication requires acquisition of grammatical knowledge as well as acquisition and practice of various sociolinguistic rules concerned with appropriateness (Eslami \& Noora, 2008, p. 326). "Even fairly advanced language learners' communicative acts regularly contain pragmatic errors, or deficits, in that they fail to convey or comprehend the intended illocutionary force. Research on pragmatic competence has proved that performing speech acts in a second language (L2) is a demanding task for L2 learners because of the inherent differences between their first language culture and the target language culture (Kasper \& Rose, 2002). These differences often cause interference and miscommunications and are even sometimes considered rude by native speakers (Boxer \& Pickering, 1995). Based on these findings, the importance of gaining pragmatic competence in the L2 classroom has been underscored, particularly by EFL researchers (Eslami-Rasekh, 1993). This could be attributed to the fact that there is a huge difference between Iranian learners' native culture and that of the second language native speakers, leading, in turn, to differences in pragmatic breakdowns in communication. Hence, this study was aimed at investigating the frequency of speech acts in high school English textbooks I, II, and III in Iran as well as their politeness levels.

To this end, the following research questions were formulated: 1) What is the frequency of speech acts and how are they distributed in the textbooks in question? 2) How are these speech acts presented linguistically? 3) To what extent do these speech acts enjoy politeness? The findings of this study may contribute to the existing body of knowledge about pragmatic competence, and also raise EFL teachers' awareness of the importance of not only attending to their students' grammatical competence, but also their pragmatic understanding.

\section{Review of literature}

Different types of competence have been defined in the SLA literature, each with their own particular focus. A good knowledge of speech acts goes beyond the first few types of competence introduced in the literature, encompassing a know-how of when and where to use what to whom. This is what has been referred to as pragmatic knowledge (Hymes, 1983) and takes into account the contextual factors that might have a bearing on the utterance used. Hymes argues that it would be simplistic to limit our view of language to the rules that would give us surface structures. The context of the situation, he argues, is as important, if not more, as linguistic forms. In what follows, we have touched upon the different types of competence that have been introduced and discussed in the literature thus far.

\subsection{Grammatical competence}

Grammatical competence was initially introduced by Chomsky which is a native speaker's knowledge of his 
An investigation into the use of speech acts and language functions in Iranian high school English textbooks

mother tongue that enables him to form and interpret words, phrases and sentences in his native language (Radford, 1997). It comprises an underlying knowledge that forms declarative sentences and an associated knowledge that can transform those declarative statements into interrogative and negative sentences. He also argued that at birth, humans are equipped with a universal grammar, and that differences among languages boil down to a number of limited parameters. The underlying idea behind this claim is that all languages are, in essence, the same, and that differences, where they exist, are to be considered as peripheral.

Hymes (1972) also criticized the Chomskyan notion of grammatical competence. He argued that it does not adequately reflect our knowledge of language. As a result, he used the term communicative competence to address contextual aspects of our language use. Thus, according to Hymes, communicative competence is the ability not only to form grammatically correct sentences using grammatical rules but also to recognize where and when to use these sentences. Below we will see the components which form our communicative competence.

\subsection{The components of the communicative competence}

According to Canale (1983), communicative competence is made up of the following components:

Grammatical competence - This kind of competence involves applying the language rules to produce grammatically correct utterances. It concerns linguistic forms per se, as created by head phrases, expanded into clauses, and in turn changed in form by the use of transformational rules. The main focus in the writings on grammatical competence deals with the idea of what rules and movements are in order for phrase structures to go from the deep structure to the surface structure.

Sociolinguistic competence - This competence concerns the appropriacy of using language in different contexts. According to Canale (1983), "appropriateness of utterances refers to both appropriateness of meaning and appropriateness of form" (p. 7). Appropriateness of meaning refers to the appropriacy of the propositional content of speech acts in a given situation. It means that people with different positions do not have the right to say whatever they feel like to. Appropriateness of form means that people with different relations should use specific forms of utterances such as formal, informal, or casual.

Discourse competence - This type of competence deals with the unity of spoken or written texts. Therefore, cohesion and coherence should be considered in this kind of competence. Cohesion refers to well-connectedness of utterances. Coherence deals with the logical relationships between different parts of a text. Thus, it is possible to have a text which is coherent without any cohesive ties as in Widdowson (1978, p. 29):

A: That's the telephone.

B: I' $m$ in the bath.

C: OK.

However, the use of cohesive ties per se does not guarantee that the text will conceptually hang together. In order for that to happen, there should be logical connections between the different utterances used in a given text. That is why coherence is more important that cohesion. We can have a coherent text devoid of cohesion, but a text enjoying optimal cohesion is not necessarily coherent.

Strategic competence - This competence refers to the knowledge of communication strategies that would compensate for deficiencies in speech. For example, when a person does not remember a specific word, he/she can use the definition of that word. For example, if a learner does not know the English word "vet", he might say "a doctor of animals".

\subsection{Speech act theory}

The theory of speech act was introduced by the British philosopher John Langshaw Austin (1962). John R. Searle, who was one of Austin's students in the 1950s, further developed the theory (Jaszczolt, 2002). The idea 
stems from a growing dissatisfaction with the assumed deficiencies of logical positivism and truth conditional semantics (Huang et al., 2007). Logical positivism claims that a sentence can be deemed meaningful only if it can be verified, or objectively assessed as true or false. Similarly, truth conditional semantics considers sentences to be true if they correctly describe states of affairs and false if their description is incorrect (Thomas, 1995). Austin (1962) was among the first to disagree with this approach, arguing that sentences like (1) to (3) do not follow the conditions above in that they are used not to describe correctly or incorrectly the states of affairs but rather to perform certain tasks:

(1) I apologize for being late,

(2) I sentence you to five years in prison,

(3) I name this ship the Princess Elizabeth.

Austin used the term speech acts to refer to such acts as apologizing, passing sentences, and naming, which is not a misnomer because these are acts which are performed through speech. He went on to refer to statements given above as performative sentences. He also observed that a certain set of conditions must be met in order for these utterances to become operative, referring to them as felicity conditions.

\subsection{Politeness theory}

The notion of politeness is a significant element in L2 learners' speech due to the fact that it involves cross-cultural differences. Thus, second language learners should become aware of this important element. Due to the constraining function of politeness in the language we use, interlocutors consciously or subconsciously are careful about certain variables which determine the form that the language will take while interacting. Goffman (1995) examined these variables under the term 'face', and defined this term as "the positive social value a person effectively claims for himself by the line others assume he has taken during a particular contact.

Following Goffman's (1995) sociological notion of face, Brown and Levinson (1987) proposed politeness theory in their seminal work entitled Politeness: Some universals in language usage. According to Brown and Levinson (1987), the theory of politeness consists of three fundamental notions including face, face threatening acts, and politeness strategies. They define the concept of face as "the public self-image that every member of a society wants to claim for himself" (p. 61). The researchers also state that face comes in two universal variations of positive and negative. While positive face refers to the hearer's desire to be appreciated or approved of (e.g., by seeking agreement, solidarity, reciprocity), negative face "represents the basic claim to territories, personal preserves, rights to non-distraction, i.e., freedom of action and freedom from imposition" (p. 61). As claimed by Brown and Levinson (1987), some speech acts such as refusals, complaints, disagreements, and criticisms can intrinsically threaten face. Hence, they are called face-threatening acts (FTAs).

\subsection{Strategies for teaching speech acts}

The model dialog - Through this useful technique, we can provide students with real examples of speech acts in use (Olshtain \& Cohen, 1991). According to Baleghizadeh (2007), at first, students listen to a dialog and then they recognize the kind of speech acts used. Next, they are presented with more dialogs without any information about the particular situation, and they have to guess the age, social status, and the relationship between the speakers.

Role-play - This technique can follow the model dialog. After students have analyzed a number of dialogs in terms of their language functions, it is time to divide them in pairs and ask them to act out these dialogs (Baleghizadeh, 2007).

Discourse completion task (DCT) - This is one of the most popular tools in interlanguage pragmatics research in which students are required to do a completion exercise and provide appropriate responses to various scenarios (Cohen, 1996). 
An investigation into the use of speech acts and language functions in Iranian high school English textbooks

Discourse rating task - This type of task requires the learners to assess different responses on a continuum (e.g. unassertive to assertive, indirect to direct, or impolite to polite) based on a given scenario (Lee and McChesney, 2000). These tasks promote language awareness; however, like model dialogs, they will not have the intended effect unless they are role played by students (Baleghizadeh, 2007).

\subsection{Research related to textbook evaluation}

Research into intercultural communication has shown that performing speech acts in a second language (L2) can be a challenging task for many L2 learners due to the inherent differences that exist between their first language (L1) and culture and the target language (TL) and culture (Kasper \& Rose, 2002). Boxer and Pickering (1995) pointed out that learners' difficulties in L2 pragmatics appear to be much less tolerated by native speakers (NS) than grammatical errors and are often considered as rudeness. These findings point to the importance of pragmatic competence and its instruction and the necessity of emphasis on pragmatics in the L2 classroom (Eslami-Rasekh, 2005). Teaching pragmatic competence is widely regarded as an integral part of learning and teaching a language, and has been widely investigated (Bardovi-Harlig, 1996; Bardovi-Harlig \& Griffin, 2005).

Many textbooks provide classroom learners with little opportunity for learning L2 pragmatics (Bardovi-Harlig, 1996). This is due to the fact that they do not practice speech acts in real contexts. Boxer and Pickering (1995) found out that textbooks generally do not contain indirect complaints (i.e. complaining about someone/something that is absent in the conversation) as a solidarity-establishing strategy. Bouton (1996) also remarked that the invitations presented in the textbook he taught are rarely the way they are in published native speaker's (NS) corpora. Also, Han (1992) found that the Korean English as Second Language (ESL) learners in her study responded to the compliments with "thank you" because this was the only response to a compliment that was present in their ELT materials.

With respect to the teaching materials and textbooks used in an Iranian context, there are a number of studies in the literature. A summary of the findings of these studies follows. Iraji (2007) conducted a research on New Interchange series, investigating to what extent the principles of CLT and TBLT approaches are taken into consideration based on the principles of communicative and task-based approach. The study indicated that the series do not follow the principles of communicative and task-based approaches as the author claimed and that they enjoyed little meta-pragmatic information.

Razmjoo (2007) investigated the extent to which the Iranian high school and private institute textbooks represented the CLT principles. The study revealed significant differences between these two learning environments. While high school textbooks were not in line with CLT principles, private institute textbooks represented the CLT principles to a great extent. Soozandehfar and Sahragard (2011) analyzed the conversation sections of Top Notch Fundamental textbooks from the pragmatic dimension of language functions and speech acts. The results showed that the conversations in these textbooks were not pragmatically efficacious and functional. Koosha and Dastjerdi (2012) investigated the use of request forms presented in Richard's Interchange Series, Books I, II, and III, widely used in Iranian foreign language teaching institutes. The results of the study indicated that the series failed to include materials which are needed for meaningful and face-saving communication when resort to different kinds of requests was required.

\section{Methodology}

The present study was conducted in an Iranian EFL context. There is a strong emphasis on English in the Iranian higher education programs by all private and state universities (Shoarinejad, 2008; Shokouhi, 1989). For the purpose of this study, high school English textbooks I, II and III by Birjandi, Soheili, Nowroozi, and Mahmoodi (2000), Birjandi, Nowroozi, and Mahmoodi (2002a), and Birjandi, Nowroozi, and Mahmoodi (2002b) were selected. All the speech acts and language functions in the three books were then analyzed. High school English textbooks I, II and III consist of nine, seven and six units respectively. Speech acts and functions at the 
Roohani, A., \& Alipour, J.

end of each unit of these textbooks became the target of analysis.

\section{Data Analysis}

Careful analysis of the speech acts in the materials was made on the basis of Searle's (1976) speech acts and Lakeoff's (1973) view of Politeness. Searle (1976) suggests the following classification of speech acts:

Representatives: They commit the speaker to something being the case. The different kinds are suggesting, putting forward, swearing, boasting, and concluding. Example: "No one makes a better cake than me"

Directives: They try to make the addressee perform an action. The different kinds are asking, ordering, requesting, inviting, advising, and begging. Example: "Could you close the window?"

Commisives: They commit the speaker to doing something in the future. The different kinds are promising, planning, vowing, betting, opposing. Example: "I'm going to Paris tomorrow"

Expressives: They express how the speaker feels about the situation. The different kinds are: thanking, apologizing, welcoming, deploring. Example: "I am sorry that I lied to you"

Declarations: They change the state of the world in an immediate way. Examples: "You are fired"

Table 1 shows the frequency and percentage of speech acts in each textbook.

\section{Table 1}

The frequency and percentage of speech acts in high school English textbooks

\begin{tabular}{lcccccccc}
\hline & Book I & $\%$ & Book II & $\%$ & Book III & $\%$ & Total & $\%$ \\
\hline Representatives & 52 & 39.09 & 40 & 36.03 & 26 & 48.14 & 118 & 39.59 \\
Directives & 58 & 43.60 & 42 & 37.83 & 24 & 44.44 & 124 & 41.61 \\
Commisives & 7 & 5.26 & 11 & 9.90 & 0 & 0 & 18 & 6.04 \\
Expressives & 16 & 12.03 & 18 & 16.21 & 4 & 7.40 & 38 & 12.75 \\
Declarations & 0 & 0 & 0 & 0 & 0 & 0 & 0 & 0 \\
\multicolumn{1}{r}{ Total } & 133 & 100 & 111 & 100 & 54 & 100 & 298 & 100 \\
\hline
\end{tabular}

As Table 1 shows, none of these textbooks presents declarative examples of speech acts while directives and representatives constitute most of the speech act instances of these three books $(41.61 \%$ and $39.59 \%$, respectively). Also, in considering these examples in each book, it was revealed that the distribution of these speech acts does not follow a pattern. For example, the number of representatives and directives in Book I and Book II are higher than those in book III. In considering commisives, as well, we can see that no example is provided in Book III. After declaratives, expressives are the second category with the fewest instances presented in these books $(12.75 \%)$. And as it is clear from Table 1, the total number of speech acts in these textbooks is 298, with Book 1 containing the highest number.

As for the second purpose of the current study, determining the politeness level of the speech acts in question, Lakoff's (1973) model was employed. According to this model, there are three different rules that speakers abide by to make sure that they have observed politeness, which are as follows:

Rule 1: Don't impose.

Rule 2: Offer options.

Rule 3: Be frank (commaradrite).

Therefore, we can examine, to some extent, the politeness level of utterances based on these rules. The results of the analysis of politeness in these textbooks are provided in table 2. 
An investigation into the use of speech acts and language functions in Iranian high school English textbooks

Table 2

The politeness of speech acts based on Lakoff's view

\begin{tabular}{lcccccccc}
\hline & Book I & $\%$ & Book II & $\%$ & Book III & $\%$ & Total & $\%$ \\
\hline The number of speech acts & 133 & 100 & 111 & 100 & 54 & 100 & 298 & 100 \\
Imposition & 12 & 9.02 & 8 & 7.20 & 6 & 11.11 & 26 & 8.72 \\
Lack of offer & 36 & 27.06 & 23 & 20.72 & 16 & 29.62 & 75 & 25.16 \\
Lack of encouragement & 70 & 52.63 & 64 & 57.65 & 34 & 62.96 & 168 & 56.37 \\
\hline
\end{tabular}

Based on Table 2, imposition, lack of offer, and lack of encouragement exist more frequently in the speech acts in Book I $(9.02 \%, 27.06 \%$, and $52.63 \%$, respectively) than the other two books. Thus, Book I, as the results show, represents more negative-face speech acts, and Book III includes fewer negative-face instances.

\section{Discussion and Conclusion}

The investigation of the frequency of the speech acts in the three books in questions revealed that the total number of speech acts in the three books is 298 (see Table 1). It should also be noted that these speech acts are not used in context, and that there is no information or picture provided to help in guessing how close a relationship there is between the speakers in the conversations. This, in turn, made it difficult to estimate the politeness level of speech acts; however, the politeness level of these speech acts was estimated by resorting to Lakoff's (1973) view of politeness.

The Iranian high school English textbooks are not communication-oriented and as a result they are not conversation-based. The speech acts analyzed in this research are included in the language functions at the end of each unit. The number of speech acts in Iranian high school English textbooks I, II, and III is 133, 111, 54 respectively. This indicates that the distribution of speech acts in these textbooks is not patterned. The percentage of speech acts shows that representatives and directives form the major share of speech acts in the series with $39.59 \%$ and $41.61 \%$ respectively. It means that these two groups of speech acts are the most prevalent ones in the two textbook series in question, while the other speech acts form a small percentage of speech acts in the two textbook series.

By looking at the language functions included in the textbook series, the following results were obtained. High school English textbooks cover a variety of language functions. A total number of 22 language functions are included in the three books ranging from basic conversational skills such as Asking Someone's Name to more challenging ones such as granting a request, rejecting a request, requesting politely and so on. Among the high school English textbooks, English I presented more language functions (13/22) than both English II (5/22) and English III (4/22). Some of the language functions did not follow any specific pattern. Thus, the distribution of speech acts across the books was not justified. Request comprises about 20 percent of language functions in the books, followed by requesting politely in book II. Then knowing people also comprises about 20 percent of the language functions, asking someone's names, finding out about people, asking about someone's family, asking about other people. Then, shopping comprises more than 13 percent of language functions in book I and II (shopping, asking about the price of things, and bargaining. Appearance and dress, and talking about a place (talking about a place, asking for directions) each also comprises about 10 percent of language functions. Finally, there are other language functions such as "on the phone, introducing a friend, talking about age, weight, hair color, asking about the weather, talking about free time, talking about transportation, and talking about one's job.

Some of the language functions presented in Book I are grammatically more difficult than those in the two other books. For example, asking about the price of things (Book II) contains structures which are grammatically simpler than those of requesting politely, granting, or rejecting a request (Book I). There are no certain criteria for selecting and grading the functions. It is not obvious on what basis functions are selected and graded. In other words, one cannot say with certainty if the criterion has been the importance and practicality of functions or the degree of being grammatically difficult. Some language functions which are supposed to be less communicatively practical are introduced prior to those functions which seem to be more practical. For example, 
Roohani, A., \& Alipour, J.

talking about one's job or asking about the weather may be more practical for learners than bargaining which precedes them.

Language functions in these three books are presented in a way that the social distance and power of speakers are not known to the learners most of the time. In order to develop learners' pragmatic competence, its two components, pragmalinguistic and sociopragmatic competences, need to be improved. To that end, speech acts can help a lot in this process. However, the speech acts included in Iran's high school English textbooks are very limited and are not efficiently contextual. So, one can conclude that these books are not suitable for serving this purpose and consequently language functions which are carried out using the speech acts are affected and limited. Therefore, it would be safe to assume that in terms of introducing language functions, these books enjoy shortcomings.

In regard to the politeness of the speech acts presented in these three books, it is difficult to decide to what extend the speech acts are polite or face-threatening because the speech acts are not mostly introduced in context and there is no explicit information concerning the relationship between the speakers. Nevertheless, based on Lakoff's view of politeness and as Table 2 shows, 8.72 percent of the speech acts suffer from imposition, 25.16 percent of them are devoid of an element of offer, and 56.37of them are devoid of an element of encouragement. These statistics show that the speech acts are not appropriate according to Lakoff's view of politeness. However, it must be noted that we cannot merely rely on these numbers, and conclude that most of the speech acts in these books are face-threatening. This is so because to be able to determine the level of imposition, deference or even frankness, we need the real context in which the conversation occurs. In conclusion, to enhance L2 learners' pragmatics competence, realistic pragmatic examples accompanying meta-pragmatic information are needed in the development of EFL textbooks. This could conceivably help learners to unravel not only the basic rules and principles of a foreign language, but also use them more effectively and successfully in a way acceptable to the target language native speakers.

\section{References}

Austin, J. L. (1962). How to do things with words? Cambridge, MA: Harvard University Press.

Baleghizadeh, S. (2007). Speech acts in English language teaching. Iranian Journal of Language Studies (IJLS), $l(2), 143-154$.

Bardovi-Harlig, K. (1996). Pragmatics and language teaching: Bringing pragmatics and pedagogy together. Pragmatics and Language Learning, 7, 21-39.

Bardovi-Harlig, K., \& Griffin, R. (2005). L2 pragmatic awareness: Evidence from the ESL classroom. System, 33, 401-415. http://dx.doi.org/10.1016/j.system.2005.06.004

Birjandi, P., Nowroozi, M., \& Mahmoodi, Gh. (2002a). High school English 2. Tehran: Iran Textbook Publisher.

Birjandi, P., Nowroozi, M., \& Mahmoodi, Gh. (2002b). High school English 3. Tehran: Iran Textbook Publisher.

Birjandi, P., Soheili, Gh., Nowroozi, M., \& Mahmoodi, Gh. (2000). High school English 1.Tehran: Iran Textbook Publisher.

Blum-Kulka, S., House, J., \& Kasper, G. (1989). Cross-cultural pragmatics: Requests and apologies. Norwood (NJ): Ablex.

Bouton, M. E. (1996). Context, ambiguity, and classical conditioning. Current Directions in Psychological Science, 3, 49-53. http://dx.doi.org/10.1111/1467-8721.ep10769943

Boxer, D., \& Pickering, L. (1995). Problems in the presentation of speech acts in ELT materials: The case of complaints. ELT Journal, 49(1), 44-58. http://dx.doi.org/10.1093/elt/49.1.44

Brown, P., \& Levinson, S. (1987). Politeness: Some universals in language use. Cambridge University Press.

Eslami-Rasekh, Z. (1993). A cross-cultural comparison of the requestive speech act realization patterns in Persian and American English. In L. Bouton, \& Y. Kachru (Eds.), Pragmatics and language learning (pp. 85-103). Urbana-Champaign, IL: Division of English as an International Language.

Eslami-Rasekh, Z. (2005). Raising the pragmatic awareness of language learners. ELT Journal, 59(2), 199-208. http://dx.doi.org/10.1093/elt/cci039 
An investigation into the use of speech acts and language functions in Iranian high school English textbooks

Eslami-Rasekh, Z., \& Noora, A. (2008). Perceived pragmatic transferability of L1 request strategies by Persian learners of English. In M. Pütz, \& J. Neff-van Aertselaer (Eds.), Developing contrastive pragmatics: Interlanguage and cross-cultural perspectives (pp. 301-333). Berlin: Mouton de Gruyter.

Goffman, E. (1995). Frame analysis: An essay on the organization of experience. New York: Harper \& Row.

Han, C. (1992). A comparative study of compliment responses: Korean females in Korean interactions and in English interactions. Working Papers in Educational Linguistics, 2, 17-31.

Huang, Y., Geng, X., \& Whinston, A. B. (2007). Defeating attacks by fixing the incentive chain. ACM Transactions on Internet Technology, 7(1). http://dx.doi.org/10.1145/1189740.1189745

Iraji, A. (2007). Pragmatic features of New Interchange: How communicative and task-based it is. Unpublished master's thesis, Shiraz University, Iran.

Jaszczolt, (2002). Against ambiguity and underspecification: Evidence from presupposition anaphora. Journal of Pragmatics, 34, 829-849. http://dx.doi.org/10.1016/S0378-2166(01)00064-9

Kasper, G., \& Rose, K. R. (2002). Pragmatic development in a second language. Michigan: Blackwell, USA.

Koosha, B.,\& Dastjerdi, H. (2012). Investigating pragmatic competence: The case of requests in Interchange Series. Asian Social Science, 8(1), 54-61.

Lakoff, R. (1973). The logic of politeness: Or minding your p's and q's. Chicago University Press.

Lee, J. S., \& McChesney, B. (2000). Discourse rating tasks: A teaching tool for developing sociocultural competence. ELT Journal, 54(2), 161-168. http://dx.doi.org/10.1093/elt/54.2.161

Olshtain, E., \& Cohen, A. D. (1991).Teaching speech act behavior to non-native speakers. In M. Celce-Murcia (Ed.), Teaching English as a second or foreign language (pp. 3-11). New York: Newbury House.

Razmjoo, S. A. (2007). High schools or private institutes' textbooks? Which fulfills communicative language teaching principles in the Iranian context? Asian EFL Journal, 9(4), 126-140.

Searle, J. (1976). A classification of illocutionary acts. Language in Society, 5, 1-23. http://dx.doi.org/10.1017/S0047404500006837

Shoarinejad, A. A. (2008). The philosophy of education. Tehran: Amir Kabir Publications.

Shokouhi, G. H. (1989). Basics and principles of education: Philosophy of teacher training. Tehran: Arasbaran Publication.

Soozandehfar, S. M., \& Sahargard, R. (2011). A textbook evaluation of speech acts and language functions in Top-Notch series. Theory and Practice in Language Studies, 1(12), 1831-1838. http://dx.doi.org/10.4304/tpls.1.12.1831-1838

Vellenga, H. (2004). Learning pragmatics from ESL and EFL textbooks: How likely? TESL-EJ, 8(2), 25-38. 
Roohani, A., \& Alipour, J. 